\title{
Состав сообществ эталонных площадок в степной зоне на территогии Государтсвенного национального природного парка «Кульсайские озера»
}

\section{Composition of communities of reference sites in the steppe zone on the territory of the State national nature park «Kulsai lakes»}

\author{
Отрадных И. Г. ${ }^{1}$, Съедина И. А. ${ }^{1}$, Уалиева Б. Б. ${ }^{2}$ \\ Otradnykh I. G. ${ }^{1}$, Syedina I. A. ${ }^{1}$, Ualyeva B. B. ${ }^{2}$ \\ 'Институт ботаники и фитоинтродукиии МОН РК, г. Алматы, Казахстан.E-mail Phyto_bot15@mail.ru \\ ${ }^{2}$ Государственный национальный природный парк «Кульсайские озера», Caты, Казахстан. E-mail kolsai_nauka@mail.ru \\ ${ }^{1}$ Institute of botany and phytointroduction MES RK, Almaty, Kasakhstan \\ ${ }^{2}$ State national nature park «Kulsai lakes», Saty, Kasakhstan
}

Peферат. Приводится описание флористического состава степных сообществ на трех эталонных участках на территории национального парка «Кульсайские озера». Видовая насыщенность колеблется от 31 до 55 видов. Ведущими семействами являются Asteraceae, Poaceae, Lamiaceae, Fabaceae.

Ключевые слова. Состав сообщества, степной пояс, эталонные участки.

Summary. The description of the floristic composition of the steppe communities on three reference sites on the territory of the Kulsai Lakes National Park is given. Species saturation ranges from 31 to 55 species. Leading families are Asteraceae, Poaceae, Lamiaceae, Fabaceae.

Key words. Community composition, reference areas, steppe zone.

Степи - это уникальные, с богатым генофондом природные комплексы. Необходимость охраны степных экосистем, особенно подверженных антропогенному влиянию, является актуальной современной проблемой. Одним из мероприятий по охране этих комплексов является проведение инвентаризации флоры и изучение структуры их растительных сообществ.

Оценка состояния растительных сообществ проводится в сравнении с участками характерной для данного природного района естественной растительности, мало затронутой воздействием человекаэталонных участков. Эталонные участки играют роль генетических резерватов. Они характеризуются разнообразием естественных растительных сообществ, служат образцами состава, структуры и продуктивности отдельных типов растительных сообществ. Также они являются хранилищем генофонда растительного мира, базой для заготовки семян в целях восстановления многовидовых травостоев на месте истощенных пастбищ, восстановления и расширенного воспроизводства исчезающих и особо ценных растительных сообществ.

Изучение растительности проводилось маршрутно-рекогносцировочным методом, описания фитоценозов проводилось в определенных точках с использованием прибора навигации GPS для определения координат. Описания проводились с учетом методических указаний (Корчагин, 1964) на площадках размером $100 \mathrm{~m}^{2}$. Для уточнения таксономической принадлежности растений проводилась гербаризация образцов. Сбор и обработка гербарного материала осуществлялись по общепринятой методике, обобщенной А. К. Скворцовым (1977). Определение видов проводилось с использованием существующих флористических сводок и определителей (Флора Казахстана, 1956-1966; Открытый атлас ..., http://www.plantarium.ru/). Номенклатура видов, родов и семейств приведена по сводкам С. К. Черепанова (1995). 
Целью работы было выявление современного состояния флоры степной зоны и анализ флористического состава территории на наличие редких и эндемичных видов растений на территории Государственного национального природного парка «Кульсайские озера» (ГНПП). ГНПП «Кульсайские озера» расположен на северном макросклоне восточной части Кунгей Алатау, климат которого определяется как резко континентальный с большой амплитудой суточных и годовых температур, преобладанием теплого периода над холодным. Северный макросклон Кунгей Алатау вместе с хребтами Кетмень и Заилийский Алатау объединяются в Заилийский округ Северо-Тянь-Шанской геоботанической провинции на основании сходства высотно-поясной структуры их растительности, а также главнейших лесных, степных и луговых формаций, слагающих основные геоботанические ландшафты данного округа (Рубцов, 1955; Ботаническая география ..., 2003), и распределение растительного покрова здесь носит резко выраженный поясный характер. В названия поясов Б. А. Быков (1985) и И. И. Ролдугин (1989) ввели доминирующие типы растительности: 1 - низкогорные степи и кустарники (до 1800 м), 2 - лесолуговой (1800-2800 м), 3 - альпийский (2800-3800 м).

Для описания нами были выделены три эталонных участка в низкогорном степном поясе на склонах с разной экспозиционной направленностью. Эталонный степная площадка № 1 находится в ущ. Саты на высоте 1642 м над ур. м. (N4307'679", E076³4'034"). Склон юго-западной экспозиции. Микрорельеф сложный, включает участки глинистого склона с мелким щебнем, выходы коренных пород (разрушенных гранитных конгломератов) и относительно пологого участка водораздела. Данная экологическая дифференциация привела к формированию трех различных по составу и строению растительных сообществ.

Первое - полынно-разнотравно-злаковое со спиреей. Почвы плотные, глинистые, с включениями мелкого щебня $(20 \%)$. Растительный покров хорошо сформирован, проективное покрытие - 90 \%. Опад слабый, имеются незначительные скопления растительных остатков под камнями. Доминантами являются полыни. В состав сообщества единично входит кустарник Spiraea hypericifolia L. Полукустарник Artemisia gmelinii Weber ex Stechem выступает в качестве доминанта. Травяной покров трехярусный. Первый ярус составляют следующие виды: Agropyron cristatum (L.) Beaub., Iris halophila Pall., Eremurus altaicus (Pall.) Steven, Carduus nutans L., Seseli schrenkianum C. A. Mey. ex Schischk., Stipa capillata L., Echium vulgare L., Aster amellus L. Второй представлен Artemisia heptapotamica Poljakov, Poa pratensis L., Poa stepposa (Kryl.) Roshev., Festuca valesiaca Gaudin, Brachypodium sylvaticum (Huds.) P. Beauv., Phleum pratense L., Geranium pratense L., Orobanche elatior Sutton, Hypericum perforatum L., Galium verum L., Medicago falcata L, Cardaria draba (L.) Desv., Potentilla orientalis Juz., Potentilla evestita Th. Wolf., Potentilla virgata Lehm., Silene graminifolia Otth, Phlomoides speciosa Rupr., Dracocephalum ruyschiana L., Allium korolkowii Regel, Papaver croceum Ledeb, Crepis sibirica L., Erysimum hieracifolium L. Третий ярус слагают Carex turkestanica Regel, Iris ruthenica Ker Gawl, Scutellaria przewalskii Juz.

На выходах коренных пород и вблизи них сформировалось сообщество растений-петрофитов: Ephedra intermedia Schrenk, Allium carolinianum DC., Allium tianschanicum Rupr, Sedum ewersii Ledeb. Diantus kuschakewiczii Regel et Schmalh., Erigeron seravschanicus M. Pop., Rhinactinidia limoniifolia (Less.) Botch., Rosularia alpestris (Kar.et Kir.) Boriss. В роли доминанта выступает Patrinia intermedia (Hornem.) Roem. ex Schult.

На водоразделе растительный покров представлен двухярусным травостоем. Верхний образован из видов: Melica transsilvanica Schur, Stipa zalesskii Wilensky, Eremopyrum orientale (L.) Jaub. ex Spach., Goniolimon eximium (Schrenk) Boiss., Rhinanthus songaricus (Sterneck) B. Fedtsch., Scabiosa ochroleuca L., Salvia deserta Schang., Plantago stepposa Kupr., Delphinium iliense Huth., Leontopodium fedtschenkoanum Beauverd., Alfredia nivea Kar. et Kir. Второй ярус формируют Thymus marschallianus Willd., Euphrasia bajankolica Juz., Oxytropis merkensis Bunge, Trifolium pratense L., единично встречаются Cuscuta еріthymum (L.) L. и Convolvulus arvensis L.

Эталонная площадка № 2 (N4300'217", E078¹7'287") расположена на склоне восточной экспозиции с уклоном в $60^{\circ}$. Каменистость $(25 \%)$ представлена разрушенными гранитами мелкой и средней фракции. Кустарниково-злаково-разнотравное сообщество с васильком. Высота 1797 м над ур. м. Проективное покрытие 80 \%. Растительный опад слабо выражен и сосредоточен вокруг кустарников, имеются остатки остей крупных злаков прошлого года. Сообщество состоит из единичных особей ку- 
старников Juniperus sabina L, Ephedra equisetina Bunge, Spiraea lasiocarpa Kar. et Kir., Rosa laxa Retz. и значительным количеством Euonymus semenovii Regel et Herd. Из травянистых видов верхний ярус представлен Calamagrostis anthoxanthoides (Munro) Regel, Linum heterosepalum Regel, Melica transsilvanica Schur, Ajania fastigiata (C. Wink1.) Poljak., Alfredia acantholepis Kar et Kir., Tragopogon songoricus S. Nikit., Phlomoides oreophila Kar. et Kir., Scabiosa ochroleuca L. Второй ярус полидоминантен и в роли доминантов выступают виды: Festuca valesiaca Gaudin, Carex polyphylla Kar. et Kir., Iris ruthenica Ker Gawl., Ziziphora clinopodioides Lam (Syn. Ziziphora bungeana Juz.), Allium oreoprasum. Schrenk, Dracocephalum integrifolium Bunge, Leontopodium fedtschenkoanum Beauverd. Polygala hybrida DC.; рассеянно встречаются: Erigeron pseudoseravschanicus Botsch., Galium verum L., Hieracium verosum Pall., Hypericum perforatum L., Euphorbia pachyrriza Kar. et Kir., Bupleurum thianschanicum Freyn., Erigeron petiolaris Vierh. В третьем ярусе участвуют почвопокровные виды Euphrasia bajankolica Juz., Scutellaria przewalskii Juz., Thymus seravschanicus Klok., для ранней весны характерны Tulipa heterophylla (Regel) Baker. и Primula algida Adams., Pedicularis alatavica Stadlm. ex Vved.

Эталонная площадка № 3. Высота 1720 м над ур. м. (N43 03'542", E078²9'042"). Пологий участок, с незначительным уклоном $\left(10-15^{\circ}\right)$ на запад. Почвы суглинистые. Травостой густой, трехъярусный, проективное покрытие 90 \%. Опад отсутствует из-за сильного зимнего выдувания ветром. Чиево-злаково-разнотравное сообщество. Первый ярус представлен: Achnaterum splendens (Trin.) Nevski, Calamagrostis epigeios (L.) Roth, Thalictrum foetidum L., Saussurea elegans Ledeb., Centaurea scabiosa L., Scabiosa ochroleuca L., Nepeta cataria L., Seseli schrenkianum (C. A. Mey ex Schicshk.) Pimenov et Sdobnina, Scorzonera transiliensis Popov.

Второй ярус слагают виды: Festuca valesiaca Gaudin, Elytrigia repens (L.) Nevski., Agropyron cristatum (L.) Beaub., Phleum pratense L, Adonis tianschanica (Adolf) Lipsch., Kochia prostrata (L.) Schrud., Geranium pratense L., Medicago lupulina L., Achillea millefolium L., Salvia deserta Schangin, Ligularia narinensis (C. Wink1.) O. Fedtch. ex B. Fedtch., Allium caeruleum Pall., Plantago stepposa Kuprian., Linum heterosepalum Regel, Linum altaicum Ledeb. ex Juz., Melandrium suaveolens (Kar.et Kir) Schischk, Thalictrum collinum Wallr., Delphinium iliense Huth, Tragopogon songoricus S. A. Nikitin, Bupleurum tianschanicum Freyn., Hypericum perforatum L., Onobrychis tanaitica Spreng., Rhinanthus songaricus (Sterneck) B. Fedtsch.

Третий ярус сложен из видов: Polygala hybrida DC., Allium korolkovii Regel, Leontopodium fedtschencoanum Beauverd, Gentiana turkestanorum Gand., Tulipa tetraphylla Regel, Crocus alatavicus Regel et Semenov, Erigeron pseudoseravschanicus Botsch., Thymus marschallianus Willd., Oxytropis merkensis Bunge, Orobanche elatior Sutton, Iris lotzyi Kanitz. В данном сообществе присутствуют виды с сокращающейся численностью, включенные в Красную книгу Казахстана: Adonis tianschanica (Самойлова, Нелина, 2014) и Crocus alatavicus (Жапарова, 2014). Особи Adonis tianschanica размещены спорадично и составляют 6 \% сообщества. Весенний эфемероид Crocus alatavicus доминирует в ранневесенней флоpe. Эндемик Заилийского и Кунгей Алатау Scorzonera transiliensis и эндемик Тянь-Шаня Linum heterosepalum встречаются редко, единичными особями.

Так как данные участки расположены в разных экологических условиях (географическое положение, особенности рельефа, ориентация склонов), видовой состав выделенных эталонных участков отличается разнообразием. Все описанные степные сообщества сравнительно богаты, их видовая насыщенность колеблется от 31 до 55 видов (табл.), принадлежащих к 33 семействам. Ведущими семействами являются Asteraceae, Poaceae, Lamiaceae, Fabaceae. Наибольшим видовым разнообразием характеризуется площадка № 1, которая насчитывает 55 видов из 51 рода из 23 семейств. Такая насыщенность видами в первую очередь связана с более разнообразным почвенным рельефом и составом почвы. Меньшим флористическим разнообразием отмечена площадка № 2, насчитывающая 31 вид из 30 родов и 20 семейств. Площадка № 3 насчитывает 38 видов из 37 родов и 17 семейств. За состоянием популяций трех редких видов (Crocus alatavicus, Adonis tianschanica, Scorzonera transiliensis) на участке № 3 необходимо вести регулярный мониторинг, чтобы проследить реакцию этих популяций на возрастающую антропогенную нагрузку. 
Количество родов и видов в семействах эталонных площадок степных сообществ

\begin{tabular}{|c|c|c|c|c|c|c|}
\hline \multirow[b]{2}{*}{ Семейство } & \multicolumn{2}{|c|}{ Площадка № 1} & \multicolumn{2}{|c|}{ Площадка № 2} & \multicolumn{2}{|c|}{ Площадка № 3} \\
\hline & $\begin{array}{c}\text { Кол-во } \\
\text { родов }\end{array}$ & $\begin{array}{c}\text { Кол-во } \\
\text { видов }\end{array}$ & $\begin{array}{c}\text { Кол-во } \\
\text { родов }\end{array}$ & $\begin{array}{c}\text { Кол-во } \\
\text { видов }\end{array}$ & $\begin{array}{c}\text { Кол-во } \\
\text { родов }\end{array}$ & $\begin{array}{c}\text { Кол-во } \\
\text { видов }\end{array}$ \\
\hline Asteraceae Dumort. & 9 & 10 & 5 & 6 & 9 & 9 \\
\hline Lamiaceae Rich. & 5 & 5 & 4 & 4 & 2 & 2 \\
\hline Poaceae Barnhart & 9 & 10 & 3 & 3 & 6 & 6 \\
\hline Fabaceae Lindl. & 3 & 3 & 1 & 1 & 3 & 3 \\
\hline Rosaceae Juss. & 2 & 4 & 1 & 1 & & \\
\hline Ranunculaceae Juss. & 1 & 1 & & & 3 & 4 \\
\hline Scrophulariaceae Juss. & 3 & 3 & 2 & 2 & 2 & 2 \\
\hline Apiaceae Lindl. & 1 & 1 & 1 & 1 & 2 & 2 \\
\hline Alliaceae J. Agardh & 1 & 3 & 1 & 1 & 1 & 2 \\
\hline Caryophyllaceae Juss. & 2 & 2 & 1 & 1 & 1 & 1 \\
\hline Hypericaceae Juss. & 1 & 1 & 1 & 1 & 1 & 1 \\
\hline Brassicaceae Burnett & 2 & 2 & & & & \\
\hline Iridaceae Juss. & 1 & 2 & 1 & 1 & 2 & 2 \\
\hline Geraniaceae Juss. & 1 & 1 & & & 1 & 1 \\
\hline Linaceae S.F. Gray & & & 1 & 1 & 1 & 2 \\
\hline Papaveraceae Juss. & 1 & 1 & & & & \\
\hline Valerianaceae Batsch & 1 & 1 & & & & \\
\hline Crassulaceae DC. & 2 & 2 & & & & \\
\hline Ephedraceae Dumort. & 1 & 1 & 1 & 1 & & \\
\hline Plumbaginaceae Juss. & 1 & 1 & & & & \\
\hline Dipsacaceae Juss. & & & 1 & 1 & 1 & 1 \\
\hline Convolvulaceae Juss. & 1 & 1 & & & & \\
\hline Polygalaceae R. Br. & & & 1 & 1 & & \\
\hline Liliaceae Juss. & & & 1 & 1 & 1 & 1 \\
\hline Rubiaceae Juss. & 1 & 1 & & & & \\
\hline Euphorbiaceae Juss. & & & 1 & 1 & & \\
\hline Celastraceae R. Br. & & & 1 & 1 & & \\
\hline Chenopodiaceae Vent. & & & & & 1 & 1 \\
\hline Cuscutaceae Dumort. & 1 & 1 & & & & \\
\hline Gentianaceae Juss. & & & & & 1 & 1 \\
\hline Asphofedelaceae Juss. & 1 & 1 & & & & \\
\hline Cupressaceae Bartl. & & & 1 & 1 & & \\
\hline Primulaceae Vent. & & & 1 & 1 & & \\
\hline Итого & 51 & 55 & 30 & 31 & 38 & 37 \\
\hline
\end{tabular}

\section{ЛИТЕРАТУРА}

Ботаническая география Казахстана и средней Азии (в пределах пустынной области) // Под ред. Рачковкой Е. И., Волковой Е. А., Храмцова В. П. - СПб., 2003. - 424с.

Быков Б. А. Еловые леса Тянь-Шаня. - Алма-Ата, 1985. -180 с.

Жапарова Н. К. Crocus alatavicus Regel et Semen. - Шафран алатауский // Красная книга Казахстана. Растения. Астана, 2014. - Т. 2, Ч. 1. - С. 345.

Корчагин A. А. Полевая геоботаника. Методическое руководство. - Изд-во: Академии Наук СССР, 1964. - Т. 3. $-531 \mathrm{c}$.

Открытый атлас сосудистых растений России и сопредельных стран. URL: http://www.plantarium.ru/ (дата обращения 06.03.2019)

Ролдугин И. И. Еловые леса Северного Тянь-Шаня (флора, классификация и динамика). - Алма-Ата, 1989 $306 \mathrm{c}$. 
Рубцов Н. И. Ботаническое районирование Северного Тянь-Шаня // Изв. АН КазССР. Сер. Биол., 1955. Вып.10. - С. 3-28.

Самойлова В. А., Нелина Н. В. Adonis tianschanica (Adolf) Lipsch. - Адонис тянь-шанский // Красная книга Казахстана. Растения. - Астана, 2014. - Т. 2, Ч. 1. - С. 49.

Скворцов А. К. Гербарий. Пособие по методике и технике. - М.: Наука, 1977. - 199 с.

Флора Казахстана. - Алма-Ата.: Изд-во АН КазССР, 1956 -1966. - Т. 1-9.

Черепанов С. К. Сосудистые растения России и сопредельных государств (в пределах бывшего СССР). - Русское издание. СПб: Мир и семья, 1995. - 992 с. 